\title{
Analisis Kemandirian Belajar Mahasiswa Sistem Informasi Pada Mata Kuliah Statistika Inferensial
}

\author{
Tifani Intan Solihati ${ }^{{ }^{*}}$, Nur Hidayanti ${ }^{1}$, Raden Kania ${ }^{2}$ \\ ${ }^{1}$ Program Studi Teknik Informatika, Universitas Banten JayaJl. Syekh Nawawi Al-Bantani, Curug Serang \\ - Banten, Telp: (o254) 217066 \\ ${ }^{2}$ Program Komputerisasi Akuntansi, Universitas Banten Jaya, Jl. Syekh Nawawi Al-Bantani, Curug \\ Serang - Banten, Telp: (o254) 217066 \\ Jl. Syekh Nawawi Al-Bantani, Curug Serang - Banten, Telp: (o254) 217066 \\ Corresponding Email: nurhidayanti@unbaja.ac.id tifaniintansolihati@unbaja.ac.id
}

\begin{abstract}
Inferential statistics learning is very important for students of the Information Systems study program at the Faculty of Computer Science at Banten Jaya University. The purpose of this study was to determine how much student confidence in learning inferential statistics, and also how much motivation the student has. Because the inferential statistics course is a subject that is considered difficult and cannot be applied in everyday life. The sample in this study was 86 participants in the statistics class in the Information Systems study program at the University of Banten Jaya. This study uses a quantitative descriptive method. The instrument used to measure the learning motivation strategy is the standard MSLQ (Motivated Strategies for Learning Questionaire) instrument. The factors of motivation and self-regulation learning are Self Efficacy, Intrinsic Factor, Test Anxiety, Cognitive Strategy Use, Self-Regulation. The mean or mean of the output of SPSS version 23 shows that Self-Efficacy, Intrinsic Factor, Cognitive Strategy Use, and SelfRegulation with good results, and the Anxiety Test produces a fairly good value.

Keywords:

Inferential; Independent; Motivation; Education; Statistics
\end{abstract}

\begin{abstract}
Abstrak
Pembelajaran statistik inferensial sangat penting untuk mahasiswa program studi Sistem Informasi pada Fakultas Ilmu Komputer di Universitas Banten Jaya. Tujuan dari penelitian ini adalah untuk mengetahui seberapa besar kepercayaan diri mahasiswa dalam belajar statistik inferensial, dan juga seberapa besar motivasi yang dimiliki mahasiswa tersebut. Karena mata kuliah statistik inferensial merupakan mata kuliah yang di anggap sulit dan tidak bisa di aplikasikan dalam kehidupan sehari-hari Sampel pada penelitian ini adalah 86 peserta kelas statistik pada program studi Sistem Infomasi di Universitas Banten Jaya. Penelitian ini menggunakan metode deskriptif kuantitatif, juga menggunakan instrument yang digunakan untuk mengukur strategi motivasi belajar adalah instrument baku MSLQ (Motivated Strategies for Learning Questionaire). Faktor-faktor dari motivasi dan pembelajaran regulasi diri adalah: Self Efficacy, Intrinsic Factor, Test Anxiety, Cognitive Strategy Use, Self-Regulation. Pada mean atau rerata dari hasil output SPSS versi 23 adalah menunjukkan bahwa Self-Efficacy, Intrinsic Factor, Cognitive Strategy Use, dan Self-Regulation dengan hasil yang baik, serta pada Test Anxiety menghasilkan nilai yang cukup baik.
\end{abstract}

Kata Kunci:

Inferensial; Kemandirian; Motivasi; Pendidikan; Statistik

\section{A. PENDAhuluan}

Filosofi pendidikan matematika sangat penting karena memberikan hal baru bagi orang awam untuk melihat dunia (Moeller, 2016). Kemampuan matematika seseorang sangat dipengaruhi penguasaan matematikanya sejak dini. Oleh karena 
itu, matematika perlu diperkenalkan dan diajarkan kepada anak sejak dini ketika mereka mulai mengenal angka. Dalam pembelajaran matematika sangat penting untuk membentuk pribadi yang berkualitas dan unggul dalam menghitung (Kurniati, 2015). Matematika merupakan ilmu dasar yang sangat penting dipelajari, karena banyak hal yang menggunakan ilmu dasar berhitung. Dari sekian banyak ilmu hitung di Perguruan Tinggi, mata kuliah statistika merupakan bagian dasar dari ilmu hitung. Mulai dari menghitung rata-rata, median, modus, kuartil, persentil, permil, mulai dari data tunggal sampai data majemuk. Mata kuliah Statistika ada dan diajarkan pada hampir semua program studi yang ada di Perguruan Tinggi. Mata kuliah ini juga sangat diperlukan untuk mendukung dalam pelaksanaan penelitian sebagai syarat penyusunan tugas akhir. Dengan adanya mata kuliah statistika, mahasiswa dapat terbantu baik dalam hal menghitung data dalam bentuk hasil maupun angket. Akan tetapi masih banyak mahasiswa yang kurang atau bahkan tidak menyukai dengan statistika karena banyak perhitungan yang harus disubtitusikan dengan rumus. Dengan begitu, dosen dikelas harus mengetahui cara dan strategi bagaimana supaya mahasiswa menyukai mata kuliah statistika, minimalnya mereka menyukai akan mata kuliah yang dasarnya berhitung. Karena statistika sangat penting dalam kehidupan sehari-hari, dan banyak sekali aplikasinya di kehidupan bermasyarakat.

Pada penelitian ini, peneliti akan menganalisis tentang kemandirian mahasiswa dalam mempelajarai mata kuliah statistik inferensial. Mata kuliah ini merupakan mata kuliah lanjutan dari mata kuliah statistika dasar.
Kemandirian adalah perilaku seseorang dalam mewujudkan keinginannya secara nyata dengan tidak bergantung pada orang lain, dalam hal ini adalah siswa tersebut mampu melakukan belajar sendiri, dapat menentukan cara belajar yang efektif, mampu melaksanakan tugas-tugas belajar dengan baik dan mampu untuk melakukan aktivitas secara mandiri (Rachmayani, 2014). Kemandirian juga merupakan pengaturan program belajar yang dapat diorganisasikan sehingga peserta didik dapat memilih dan menentukan bahan dan kemajuan belajarnya (Ch. Ismaniati, Sungkono, 2015). Kemandirian dalam berhitung dan mengenal angka sangat diperlukan, apalagi jika diperkenalkan di usia dini pada taman kanak-kanak. Berhitung sambil bernyanyi, berhitung sambil mewarni, dan lain sebagainya. Dengan terlatihnya anak-anak dalam mengenal angka, sampai duduk di bangku kuliah mereka akan terbiasa mandiri dalam mengerjakan soal matematika atau hitungan dari tingkat kesulitan rendah sampai tingkat kesulitan yang sangat kompleks.

Ada beberapa indikator yang dapat digunakan untuk mengukur kemandirian belajar, yaitu: 1) inisiatif belajar, 2) mendiagnosa kebutuhan belajar, 3) menetapkan target dan tujuan belajar, 4) memonitor, mengatur dan mengontrol kemajuan belajar, 5) memandang kesulitan sebagai tantangan, 6) memanfaatkan dan mencari sumber yang relevan, 7) memilih dan menerapkan strategi belajar, 8) mengevaluasi proses dan hasil belajar dan 9) memiliki selfconcept atau konsep diri (Sumarmo, 2004). Sebagai pendidik dalam membantu para peserta didik dengan mengevaluasi pencapaian, keterampilan, dan pemhaman, pendidik 
juga membantu peserta didik dalam kemandirian belajar (Bonds, Bonds, \& Peach, 1992).

Dalam pembelajaran matematika tidak hanya kemandirian yang diperlukan, tetapi juga motivasi belajar yang sangat diperlukan oleh semua mahasiswa. Motivasi adalah dorongan yang menyebabkan terjadinya suatu perbuatan guna mencapai suatu tujuan. Dalam hal ini, yang dimaksud motivasi adalah suatu kemauan seseorang untuk melakukan aktivitas belajar agar prestasi belajar dapat dicapai semaksimal mungkin (Mulyaningsih, 2014). Ciri-ciri peserta didik yang bermotivasi belajar tinggi akan selalu bekerja keras, tangguh, tidak mudah putus asa, berorientasi ke masa depan, menyenangi tugas yang memiliki tingkat kesulitan sedang, dan menyukai balikan yang cepat mengenai prestasinya juga bertanggung jawab dalam memecahkan masalah (Mulyaningsih, 2014). Berdasarkan paparan diatas, motivasi merupakan dorongan untuk melakukan sesuatu hal yang positif dari dalam diri, dan dilakukan dengan sesuai keinginan dan kemauan yang kuat. Dua hal penting yakni motivasi dan strategi pembelajaran, pada faktor motivasi memiliki 6 bagian penting dan 9 bagian penting pada strategi pembelajaran yang digunakan subskala modular dan dapat digunakan secara bersamaan, tergantung pada tujuan para peneliti (Karadeniz, Büyüköztürk, Akgün, Çakmak, \& Demirel, 2008).

Instrument yang digunakan dalam penelitian ini dalam hal mengukur motivasi belajar mahasiswa menggunakan instrument MSLQ (Motivated Strategi for Learning Questionaire), instrument yang terdiri dari 44 pernyataan dengan skala 7 , dengan skala 1 yakni: "sama sekali tidak benar" dengan skala 7 yakni: "sangat benar untuk saya”. Pertanyaanpertanyaan tersebut terbagi menjadi 5 faktor, meliputi Self Efficacy, Intrinsic Factor, Test Anxiety, Cognitive Strategy Use, Dan Self-Regulation (Paul R. Pintrich and Elisabeth V. De Groot, 1990). Motivasi Strategi untuk Belajar Kuisioner (MSLQ) memiliki sejarah panjang yang digunakan dalam ilmu psikologi pendidikan, akan tetapi beberapa penelitian telah memeriksa struktur faktor penting dari seluruh skala menggunakan data dari satu administrasi instrumen, meskipun menggunakan subskala secara individual didorong oleh pencipta instrumen, praktik ini telah menghasilkan bukti sedikit demi sedikit untuk struktur faktor penting (Hilpert, Stempien, Van Der Hoeven Kraft, \& Husman, 2013). Dalam penelitian ini, peneliti mengambil semua item MSLQ untuk sampel mahasiswa program studi sistem informasi semester 3 fakultas ilmu komputer, Universitas Banten Jaya yang sedang mengampu mata kuliah statistika inferensial. Tujuan dari penelitian ini adalah untuk mengetahui seberapa besar kepercayaan diri mahasiswa dalam belajar statistik inferensial, dan juga seberapa besar motivasi yang dimiliki mahasiswa tersebut. Karena mata kuliah statistik inferensial merupakan mata kuliah yang di anggap sulit dan tidak bisa di aplikasikan dalam kehidupan seharihari Sampel pada penelitian ini adalah 86 peserta kelas statistik pada program studi Sistem Infomasi di Universitas Banten Jaya.

\section{B. METODE}

Penelitian ini menggunakan metode kuantitatif dengan menggunakan analisa deskriptif dan analisa faktor dengan mencari Output 
menggunakan Software SPSS versi 23. Dalam analisa deskriptif untuk menarik kesimpulan tentang faktor-faktor pada MSLQ untuk setiap pernyataan yang ada tanggapan responden dibagi dalam lima kelas dengan panjang kelas $=\frac{7-1}{5}=1,2$. Kategori responden adalah:

\section{Tabel 1. Kategori Responden}

\begin{tabular}{|l|c|}
\hline Sangat Baik & $5,8 \leq \mathrm{X} \leq 7$ \\
\hline Baik & $4,6 \leq \mathrm{X} \leq 5,8$ \\
\hline Cukup Baik & $3,4 \leq \mathrm{X} \leq 4,6$ \\
\hline Buruk & $2,2 \leq \mathrm{X} \leq 3,4$ \\
\hline Sangat Baik & $1 \leq \mathrm{X} \leq 2,2$ \\
\hline
\end{tabular}

Pada penelitian ini terdapat analisis faktornya dilakukan beberapa tahapan analisis terhadap hasil output SPSS versi 23 tentang Correlation Matrix, KMO dan Bartleet's test, Table Anti Image Matrices, Tabel Communalities, Tabel Total Variance Explained, Tabel Component Matrix, Tabel Rotated Matrix dan Tabel Component Transformation Matrix (jika ada lebih satu Component). Populasi yang digunakan adalah mahasiswa Fakultas Ilmu Komputer, sedangkan sample dari penelitian ini adalah 86 mahasiswa Fakultas Ilmu Komputer yang mengontrak Mata Kuliah Statistika Inferensial 2019-2020.

Instrument yang digunakan pada pengukuran strategi motivasi belajar adalah instrument MSLQ (Motivated Strategies for Learning Questionaire) dari Printrich dan DeGroot (Paul R. Pintrich and Elisabeth V. De Groot, 1990). Instrument ini terdiri dari 44 pernyataan dengan skala 7 , dengan skala 1 memiliki arti "sama sekali tidak benar" dan skala 7 memiliki arti "sangat benar". Pernyataan terbagi ke dalam 5 variabel, yakni:

\section{Tabel 2. Motivated Strategies for Learning Questionaire}

\begin{tabular}{|l|l|}
\hline Self-Efficacy & $2,6,8,9,11,13,16,18,19$ \\
\hline Intrinsic Factor & $1,4,5,7,10,14,15,17,21$ \\
\hline Test Anxiety & $3,12,20,22$ \\
\hline Cognitive & $23,24,26,28,29,30,31$ \\
Strategy Use & $34,36,39,41,42,44$ \\
\hline Self-Regulation & $25,27,32,33,35,37,38$ \\
& 40,43 \\
\hline
\end{tabular}

Akan tetapi peneliti mengelompokkan nomor-nomor tersebut kedalam bagiannya, sehingga memudahkan peneliti untuk merekap untuk mendapatkan hasil yang cepat, tepat dan akurat.

\section{HASIL PEMBAHASAN \\ 1. Hasil Analisa Descriptive}

Analisis statistik deskripsi diperlukan untuk mengetahui bagaimana sebaran data penelitian yang disebar melalui angket. Analisis ini dilakukan dalam penelitian yang meliputi: mean, standar deviasi, analysis $N$. Analisis deskripsi sederhana ini dilakukan berdasarkan table dibawah ini:

Tabel 3. Descriptive Statistics

\begin{tabular}{|l|r|r|r|}
\hline & Mean & Std. Deviation & Analysis N \\
\hline Self-Efficacy (SE) & 47.41 & 6.481 & 86 \\
\hline Intrinsic Factor (IF) & 50.17 & 6.169 & 86 \\
\hline Test Anxiety (TA) & 15.41 & 4.839 & 86 \\
\hline Cognitive Strategy Use (CSU) & 69.45 & 8.042 & 86 \\
\hline Self-Regulation (SR) & 44.50 & 5.865 & 86 \\
\hline
\end{tabular}

a. Variabel Efikasi Diri (Self-Efficacy)

Pada nilai rata-rata untuk variabel Efikasi Diri (Self-Efficacy) adalah 47,41. Pada Efikasi Diri (Self-Efficacy) terdapat 9 pernyataan, maka rerata tanggapan per pernyataan adalah $\frac{47,41}{9}=5,27$. Hal ini berarti secara ratarata, mahasiswa program studi sistem informasi Universitas Banten Jaya mempunyai nilai Efikasi Diri (Self- 
Efficacy) yang baik (berdasarkan table 1).

b. Variabel Faktor Intrinsik (Intrinsic Factor)

Pada nilai rata-rata untuk variabel Faktor Intrinsik (Intrinsic Factor) adalah 50,17. Pada Faktor Intrinsik (Intrinsic Factor) terdapat 9 pernyataan, maka akan diperoleh rata-rata tanggapan per pernyataan adalah $\frac{50,17}{9}=5,57$. Hal ini berarti secara rerata, mahasiswa program studi sistem informasi Universitas Banten Jaya mempunyai nilai Faktor Intrinsik (Intrinsic Factor) yang baik (berdasarkan table 1).

c. Variabel Uji Kecemasan (Test Anxiety).

Pada nilai rata-rata untuk variabel Test Anxiety adalah 15,41. Pada Test Anxiety terdapat 4 pernyataan, maka akan diperoleh rata-rata tanggapan per pernyataan adalah $\frac{15,41}{4}=3,85$. Hal ini berarti secara rerata, mahasiswa program studi sistem informasi Universitas Banten Jaya mempunyai nilai mempunyai Test Anxiety yang cukup baik (berdasarkan table 1).

d. Variabel Penggunaan Strategi Kognitif (Cognitive Strategy Use). Pada nilai rata-rata untuk faktor Penggunaan Strategi Kognitif (Cognitive Strategy Use) adalah
69,45. Pada Penggunaan Strategi Kognitif (Cognitive Strategy Use) terdapat 13 pernyataan, maka akan diperoleh rata-rata tanggapan per pernyataan adalah $\frac{69,45}{13}=5,34$. Hal ini berarti secara rerata, mahasiswa program studi sistem informasi Universitas Banten Jaya mempunyai nilai Penggunaan Strategi Kognitif (Cognitive Strategy Use) yang baik (berdasarkan table 1).

e. Faktor Self-Regulation

Pada nilai rata-rata untuk variabel Regulasi Diri (Self-Regulation) adalah 44,50. Pada Regulasi Diri (Self-Regulation) terdapat 9 pernyataan, maka akan diperoleh rata-rata respon per pernyataan adalah $\frac{44,50}{9}=4,94$. Berarti menurut rata-rata, mahasiswa program studi sistem informasi Universitas Banten Jaya mempunyai nilai Regulasi Diri (Self-Regulation) dengan nilai baik (berdasarkan table 1).

\section{Hasil Analisis Faktor}

Pada hasil analisis SPSS versi 23 dapat di analisis dengan memaparkan isi dari hasil Output. Untuk menentukan variabel yang lebih mendominasi? Apakah motivasi atau strategi regulasi diri mahasiswa Program Studi Sistem Informasi di Universitas Banten Jaya dalam pembelajaran statistika inferensial. 
Tabel 4. Correlation Matrix

\begin{tabular}{|c|c|c|c|c|c|c|}
\hline & & $\begin{array}{c}\text { Self- } \\
\text { Efficacy } \\
\end{array}$ & $\begin{array}{c}\text { Intrinsic } \\
\text { Factor } \\
\end{array}$ & Test Anxiety & $\begin{array}{c}\text { Cognitive } \\
\text { Strategy Use } \\
\end{array}$ & Regulation \\
\hline \multirow{5}{*}{$\begin{array}{l}\text { Correl } \\
\text { ation }\end{array}$} & Self-Efficacy & 1.000 & 488 & -.210 & .283 & 332 \\
\hline & $\begin{array}{l}\text { Intrinsic } \\
\text { Factor }\end{array}$ & .488 & 1.000 & -.091 & .514 & .326 \\
\hline & Test Anxiety & -210 & -091 & 1.000 & 022 & 103 \\
\hline & $\begin{array}{l}\text { Cognitive } \\
\text { Strategy Use }\end{array}$ & .283 & .514 & .022 & 1.000 & .526 \\
\hline & $\begin{array}{l}\text { Self- } \\
\text { Regulation }\end{array}$ & .332 & .326 & .103 & .526 & 1.000 \\
\hline \multirow{5}{*}{$\begin{array}{l}\text { Sig. } \\
\text { (1- } \\
\text { tailed) }\end{array}$} & Self-Efficacy & & .000 & .026 & .004 & .001 \\
\hline & $\begin{array}{l}\text { Intrinsic } \\
\text { Factor }\end{array}$ & .000 & & .201 & .000 & .001 \\
\hline & Test Anxiety & .026 & .201 & & .422 & .173 \\
\hline & $\begin{array}{l}\text { Cognitive } \\
\text { Strategy Use }\end{array}$ & .004 & .000 & .422 & & .000 \\
\hline & $\begin{array}{l}\text { Self- } \\
\text { Regulation }\end{array}$ & .001 & .001 & .173 & .000 & \\
\hline
\end{tabular}

a. Determinant $=355$

Dari data table diatas, dapat diuraikan bahwa pada semua variabel terlihat saling berhubungan satu sama lain. Karena determinan mendekati nol. Contohnya pada korelasi antara Efikasi
Diri (Self-Efficacy) dengan Faktor Intrinsik (Intrinsic Factor) pada nilai o,488 memiliki sifat baik dengan nilai signifikan $0,000<0,05$.

Tabel 5. Tabel KMO and Bartlett's Test

\begin{tabular}{|l|l|r|}
\hline Kaiser-Meyer-Olkin Measure of Sampling Adequacy. & 635 \\
\hline Bartlett's Test of Sphericity & Approx. Chi-Square & 85.544 \\
\cline { 2 - 3 } & Sf & 10 \\
& Sig. & .000 \\
\hline
\end{tabular}

Berdasarkan data dari table $\mathrm{KMO}$ and Bartlett's Test, terdapat nilai Chi-Square yakni 85,544 mempunyai signifikan o,00o < 0,05, sehingga dapat dilakukan analisis selanjutnya. Nilai Kaiser-Meyer-
Olkin $(\mathrm{KMO})=0,635$. Sehingga layak dilakukan analisis variabel ke jenjang berikutnya.

Tabel 6. Tabel Anti-Image Matrices 


\begin{tabular}{|c|c|c|c|c|c|c|}
\hline & & Self-Efficacy & $\begin{array}{c}\text { Intrinsic } \\
\text { Factor }\end{array}$ & Test Anxiety & $\begin{array}{c}\text { Cognitive } \\
\text { Strategy Use }\end{array}$ & $\begin{array}{c}\text { Self- } \\
\text { Requation }\end{array}$ \\
\hline \multirow{5}{*}{$\begin{array}{l}\text { Anti- } \\
\text { image } \\
\text { Covari } \\
\text { ance }\end{array}$} & Self-Efficacy & .689 & -.255 & .180 & .034 & -.164 \\
\hline & $\begin{array}{l}\text { Intrinsic } \\
\text { Factor }\end{array}$ & -.255 & .608 & .020 & -.246 & .009 \\
\hline & Test Anxiety & .180 & .020 & 922 & -.006 & -.130 \\
\hline & $\begin{array}{l}\text { Cognitive } \\
\text { Strategy Use }\end{array}$ & .034 & -.246 & -.006 & .590 & -.273 \\
\hline & $\begin{array}{l}\text { Self- } \\
\text { Regulation }\end{array}$ & -.164 & .009 & -.130 & -.273 & .668 \\
\hline \multirow{5}{*}{$\begin{array}{l}\text { Anti- } \\
\text { image } \\
\text { Correl } \\
\text { ation }\end{array}$} & Self-Efficacy & $639^{\mathrm{a}}$ & -393 & .226 & .053 & -.242 \\
\hline & $\begin{array}{l}\text { Intrinsic } \\
\text { Factor }\end{array}$ & -.393 & $.655^{\mathrm{a}}$ & .027 & -.411 & .014 \\
\hline & Test Anxiety & 226 & .027 & $.444^{\mathrm{a}}$ & -.008 & -.166 \\
\hline & $\begin{array}{l}\text { Cognitive } \\
\text { Strategy Use }\end{array}$ & .053 & -.411 & -.008 & $.632^{\mathrm{a}}$ & -.435 \\
\hline & $\begin{array}{l}\text { Self- } \\
\text { Rugulation }\end{array}$ & -.242 & .014 & -.166 & -.435 & $.646^{\mathrm{a}}$ \\
\hline
\end{tabular}

Pada table diatas, nilai Measures of Sampling Adequacy (MSA) untuk Uji Kecemasan (Test Anxiety) nilai MSA adalah o,444 masih dibawah atau kurang dari o,5 maka variable Uji Kecemasan (Test Anxiety) sehingga harus mengulangi langkah analisis faktor kembali, dengan analisis faktor dengan SPSS versi 23 tanpa mengikuti variable Uji Kecemasan (Test Anxiety).

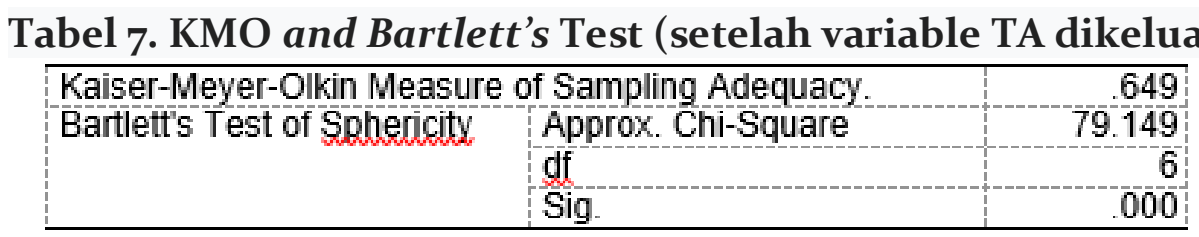

Pada table diatas, nilai Kaiser-MeyerOlkin $(\mathrm{KMO})=0,649$ adalah lebih besar dari nilai KMO sebelum variable Test Anxiety dihilangkan. Hal ini berarti terdapat pengurangan variable Test Anxiety adalah sangat cukup beralasan, atau keempat variable yang lain yakni, Self-Efficacy, Intrinsic Factor, Cognitive Strategy Use, dan Self-Regulation pantas untuk dilakukan analisis variabel selanjutnya.

Tabel 8. Anti-Image Matrices

\begin{tabular}{|c|c|c|c|c|c|}
\hline & & Self-Efficacy & $\begin{array}{l}\text { Intrinsic } \\
\text { Factor }\end{array}$ & $\begin{array}{c}\text { Cognitive } \\
\text { Strategy Use }\end{array}$ & $\begin{array}{c}\text { Self- } \\
\text { Regulation }\end{array}$ \\
\hline \multirow{4}{*}{$\begin{array}{l}\text { Anti- } \\
\text { image } \\
\text { Covaria } \\
\text { nce }\end{array}$} & Self-Efficacy & .727 & -.273 & 037 & -150 \\
\hline & Intrinsic Factor & -273 & 608 & -246 & .012 \\
\hline & $\begin{array}{l}\text { Cognitive } \\
\text { Strategy Use }\end{array}$ & .037 & -.246 & .590 & -.282 \\
\hline & Self-Regulation & -.150 & .012 & -.282 & .687 \\
\hline \multirow{4}{*}{$\begin{array}{l}\text { Anti- } \\
\text { image } \\
\text { Correlati } \\
\text { on }\end{array}$} & Self-Efficacy & $664^{2}$ & -.410 & .056 & -.212 \\
\hline & Intrinsic Factor & -.410 & $643^{\mathrm{a}}$ & -411 & .019 \\
\hline & $\begin{array}{l}\text { Cognitive } \\
\text { Strategy Use }\end{array}$ & .056 & -.411 & $.628^{\mathrm{a}}$ & -.443 \\
\hline & Self-Regulation & -.212 & .019 & -.443 & $671^{\mathrm{a}}$ \\
\hline
\end{tabular}

a. Measures of Sampling Adequacy(MSA) 
Hasil output SPSS pada table Anti-Image Matrices diatas memperlihatkan bahwa nilai empat variable sudah diatas atau lebih dari o,5 sehingga dapat dilakukan analisis selanjutnya.

Tabel 9. Communalities

\begin{tabular}{|l|r|r|}
\hline & Initial & $\begin{array}{c}\text { Extractio } \\
\mathrm{n}\end{array}$ \\
\hline Self-Efficacy & 1.000 & .469 \\
\hline Intrinsic Factor & 1.000 & .620 \\
\hline Cognitive Strategy Use & 1.000 & .625 \\
\hline Self-Regulation & 1.000 & .526 \\
\hline Extraction Method: Principal Component Analysis. \\
\hline
\end{tabular}

Pada table diatas terlihat bahwa Efikasi Diri (Self-Efficacy) masih memiliki nilai kurang dari 0,5. Sehingga harus dilakukan analisis faktor kembali. Communalities harus lebih besar dari 0,5 .

Tabel 1o. Communalities

\begin{tabular}{|l|r|r|}
\hline & Initial & Extraction \\
\hline Intrinsic Factor & 1.000 & 576 \\
\hline Cognitive Strategy Üe & 1.000 & 751 \\
\hline Self-Regulation & 1.000 & 589 \\
\hline Extraction Method: Principal Component Analysis. \\
\hline
\end{tabular}

Pada table Communalities diatas terdapat data setelah variable Efikasi Diri (Self-Efficacy) dikeluarkan. Table diatas menunjukkan bahwa nilai Communalities telah memenuhi syarat dengan nilai lebih besar dari o,5 jadi dapat dilakukan analisis selanjutnya. Maka dari itu bahwa keseluruhan variable yang digunakan memiliki hubungan kuat dengan variabel yang terbentuk (semakin besar nilai Communalities semakin baik juga hubungan yang dimiliki) (Louise $\mathrm{M}$. Saija, 2018).

Tabel 11. Total Variance Explained

\begin{tabular}{|c|c|c|c|c|c|c|}
\hline \multirow{2}{*}{$\begin{array}{l}\text { Comp } \\
\text { onent }\end{array}$} & \multicolumn{3}{|c|}{ Initial Eigenvalues } & \multicolumn{3}{|c|}{ Extraction Sums of Squared Loadings } \\
\hline & Total & $\%$ of Variance & Cumulative $\%$ & Total & $\%$ of Variance & Cumulative $\%$ \\
\hline 1 & 1.916 & 63.868 & 63.868 & 1.916 & 63.868 & 63.868 \\
\hline 2 & .674 & 22.471 & 86.339 & & & \\
\hline 3 & .410 & 13.661 & 100.000 & & & \\
\hline
\end{tabular}

Pada table Total Variance Explained terlihat jelas bahwa presentase Variance (keragaman) total yang dapat dijelaskan oleh keragaman variabel-variabel yang terbentuk dengan memperhatikan komponen yang dimiliki oleh eigenvalues lebih besar dari 1. Jadi dari tabel diatas terlihat bahwa komponen 1 saja yang diperhatikan dan $63,868 \%$ dengan keragaman total dijelaskan. 
Tabel 12. Component Matrix

\begin{tabular}{|l|r|}
\hline \multirow{2}{*}{} & Component \\
\cline { 2 - 2 } & $\mathbf{1}$ \\
\hline Intrinsic Factor & .866 \\
\hline Cognitive Strategy Use & .767 \\
\hline Self-Regulation & .759 \\
\hline Extraction Method: Principal Component Analysis. \\
\hline a. 1 components extracted. \\
\hline
\end{tabular}

Pada tabel diatas Component Matrix menunjukkan besarnya korelasi tiap variable dalam faktor yang terbentuk (loading factor). Terlihat bahwa terlihat pada nilai variable Intrinsik Faktor (Intrinsic Factor) memiliki korelasi tertinggi yaitu o,866 artinya variable faktor intrinsik (Intrinsic Factor) atau faktor intrinsic atau motivasi intrinsik yang digunakan memberi pengaruh yang paling kuat terhadap motivasi dan dorongan dari dalam diri mahasiswa program studi Sistem Informasi, Fakultas Ilmu Komputer di Universitas Banten Jaya dalam pembelajaran Statistika Inferensial.

\section{SIMPULAN}

\section{Simpulan}

Kesimpulan hasil penelitian pada mahasiswa Program Studi Sistem Informasi pada Fakultas Ilmu Komputer di Universitas Banten Jaya adalah:

a. Pada mean atau rerata dari hasil output SPSS versi 23 adalah menunjukkan bahwa Efikasi Diri (Self-Efficacy), Faktor Intrinsik (Intrinsic Factor), Penggunaan Strategi Kognitif (Cognitive Strategy Use), dan Regulasi Diri (SelfRegulation) dengan hasil baik, serta pada Uji Kecemasan (Test Anxiety) dengan hasil cukup baik.

b. Pada variable faktor intrinsik (Intrinsic Factor) motivasi merupakan pengaruh yang paling kuat dan timbul dari dalam diri mahasiswa tersebut. Motivasi merupakan faktor yang paling dominan dan faktor dari dalam diri mahasiswa tersebut.

\section{Saran}

Berdasarkan penelitian yang telah dilaksanakan, maka penelitian memberikan saran untuk jadi bahan pertimbangan dalam memperbaiki proses pembelajaran, yaitu:

a. Bagi Perguruan Tinggi

Metode pembelajaran apa pun bisa digunakan untuk mengukur sejauh mana kemandirian dan motivasi belajar mahasiswa, untuk meingkatkan kualitas proses dan hasil belajar.

b. Bagi Dosen

Dosen bisa menggunakan dan menerapkan pendekatan dan model pembelajaran yang lebih bervariasi lagi untuk mengetahui sejauh mana kemandirian dan motivasi mahasiswa dalam memahami mata kuliah.

c. Bagi Mahasiswa

Bisa mengikuti semua mata kuliah yang dikontrak selama satu semester. dengan metode apapun dosen tersebut mengajar, mahasiswa bisa dan mampu mengikuti kegiatan belajar mengajar dengan berbagai macam kemandirian dan motivasi yang dimiliki oleh setiap mahasiswa.

d. Bagi Peneliti 
Semua peneliti bisa menggunakan berbagai metode atau cara dalam mengajar. Karena untuk mengukur tingkat kemandirian dan motivasi mahasiswa dapat menggunakan berbagai metode yang sudah banyak digunakan pada umumnya.

\section{DAFTAR PUSTAKA}

Bonds, C. W., Bonds, L. G., \& Peach, W. (1992). Metacognition: Developing Independence in Learning. The Clearing House: A Journal of Educational Strategies, Issues and Ideas, 66(1), 56-59. https://doi.org/10.108o/ooo98655.1 992.9955930

Ch. Ismaniati, Sungkono, dan D. W. (2015). MODEL BLENDED LEARNING UNTUK MENINGKATKAN KEMANDIRIAN BELAJAR DAN DAYA TARIK DALAM PERKULIAHAN. JURNAL PENELITIAN ILMU PENDIDIKAN, $8(2)$, 19-27. Retrieved from https://journal.uny.ac.id/index.ph p/jpip/article/viewFile/8269/6904

Hilpert, J. C., Stempien, J., Van Der Hoeven Kraft, K. J., \& Husman, J. (2013). Evidence for the latent factor structure of the mslq: A new conceptualization of an established questionnaire. SAGE Open, 3(4). https://doi.org/10.1177/21582440135 10305

Karadeniz, Ş., Büyüköztürk, Ş., Akgün, Ö. E., Çakmak, E. K., \& Demirel, F. (2008). The Turkish adaptation study of motivated strategies for learning questionnaire (MSLQ) for 12-18 year old children:Results of confirmatory factor analysis $\mathbf{1}$. Turkish Online Journal of Educational Technology, 7(4), 108117.

Kurniati, A. (2015). Mengenalkan Matematika Terintegrasi Islam
Kepada Anak Sejak Dini. Suska Journal of Mathematics Education, 1(1), 1-8.

Louise M. Saija. (2018). ANALISIS TERHADAP KEMANDIRIAN MAHASISWA DALAM BELAJAR STATISTIKA. Pedagogik, 1(2). https://doi.org/https://doi.org/10.3 5974/jpd.v2i2

Moeller, P. E.-O. S.-J. P. V. B.-M. B.-R. M.-L. kvasz-R. (2016). The Philosophy of Mathematics Education.

https://doi.org/10.1007/978-3-31940569-9

Mulyaningsih, I. E. (2014). Pengaruh Interaksi Sosial Keluarga, Motivasi Belajar, dan Kemandirian Belajar terhadap Prestasi Belajar. Jurnal Pendidikan Dan Kebudayaan, 2o(4), 441.

https://doi.org/10.24832/jpnk.v2oi4 .156

Paul R. Pintrich and Elisabeth V. De Groot. (1990). Motivational and Self-Regulated Learning Components of Classroom Academic Performance. Journal of Educational Psychology, 82(1), 3340.

Rachmayani, D. (2014). Penerapan Pembelajaran Reciprocal Teaching Untuk Meningkatkan Kemampuan Komunikasi Matematis Dan Kemandirian Belajar Matematika Siswa. Jurnal Pendidikan Unsika, 2(1), 13-23.

Sumarmo, U. (2004). Kemandirian Belajar: Apa, Mengapa, dan Bagaimana dikembangkan pada Peserta Didik Oleh: Utari Sumarmo, FPMIPA UPI. Academia.Edu, $\quad 8, \quad$ 1-9. https://doi.org/10.1111/j.10958312.2011.01677.X 